NASA Technical Memorandum 105909

AIAA-93-0692

$$
\begin{gathered}
1 N-35 \\
130521
\end{gathered}
$$

\title{
Effect of Vaporization on Cryogenic Spray Dropsize Measurement
}

Robert D. Ingebo Lewis Research Center Cleveland, Ohio

Prepared for the 31st Aerospace Scjences Meeting and Exhibit sponsored by the American Institute of Aeronautics and Astronautics Reno, Nevada, January 11-14, 1993 


\title{
EFFECT OF VAPORIZATION ON CRYOGENIC SPRAY DROPSIZE MEASUREMENT
}

\author{
Robert D. Ingebo \\ National Aeronautics and Space Administration \\ Lewis Research Center \\ Cleveland, Ohio 44135
}

\section{Abstract}

The fluid mechanics of multiphase flow breakup of liquid nitrogen, $\mathrm{LN}_{2}$, jets injected into sonic velocity nitrogen gasflow, was experimentally investigated. A scattered-light scanning instrument was used to measure the characteristic dropsize, $\mathrm{D}_{\mathrm{v} .5}$, of $\mathrm{LN}_{2}$ sprays and to determine the effect of droplet vaporization on experimental dropsize measurements. Under sonic gas-velocity conditions, liquid-jet breakup occurred in the regime of aerodynamic stripping. As a result, the following correlation of volume-median drop diameter, $D_{v .5}$, with atomizing gas flowrate, $W_{g}$, was derived for two-fluid atomizers; $D_{v .5}^{-1}=k_{c} W_{g}^{n}$, where proportionality constant $k_{c}$ and exponent $n$ are functions of droplet vaporization rate. In this study, partially vaporized sprays were investigated and it was found that $\mathrm{n}=1.11$, which is considerably less than the value of 1.33 that is predicted by atomization theory. This was attributed to the evaporative loss of very small droplets. As a result, the following expression was obtained experimentally: $D_{v .5}^{-1}=301 \mathrm{~W}_{g}^{1.11}$. Values of $D_{v .5}$, that existed prior to partial vaporization of the $\mathrm{LN}_{2}$ sprays, were calculated and the following expression was derived for originally unvaporized $\mathrm{LN}_{2}$ sprays: $D_{\mathrm{v} .5}^{-1}=285 \mathrm{~W}_{\mathrm{g}}^{1.33}$. This expression agrees well with atomization theory that predicts $n=1.33$, for liquid jet breakup in high-velocity gasflow.

\section{Nomenclature}

$$
\begin{array}{ll}
\text { a } & \text { acceleration, } \mathrm{cm} / \mathrm{sec}^{2} \\
\mathrm{C}_{\mathrm{d}} & \text { drag coefficient } \\
\mathrm{D}_{\mathbf{v} .5} & \text { volume median drop diameter } \\
\mathrm{k}_{\mathrm{c}} & \text { correlation coefficient, } \mathrm{sec} / \mathrm{g}-\mathrm{cm} \\
\mathrm{m} & \text { mass of characteristic } \mathrm{LN}_{2} \text { droplet, } \mathrm{g} \\
\text { n } & \text { exponent for weight flow of fluid }
\end{array}
$$

$\mathrm{Nu}$ heat transfer Nusselt number, based on $D_{v .5}$

Re Reynolds number based on $D_{v .5}$

$t$ vaporization time, sec

$\mathrm{V}$ fluid velocity, $\mathrm{cm} / \mathrm{sec}$

Copyright (c) 1992 by the American Institute of Acronautic and Astronautics. Inc. No copyright is asserted in the United States under Title 17, U.S. Code. The U.S. Government has a royalty-free license to excrcise all rights under the copyright claimed herein for Guvernmental purposes

All sther rights are reserved by the copyright owner
W weight flow of fluid, $8 / \mathrm{sec}$

$\overline{\mathrm{x}} \quad$ axial downstream spray sampling distance

$\gamma \quad$ kinematic viscosity, $\mathrm{cm}^{2} / \mathrm{sec}$

$\rho$ fluid density, $\mathrm{g} / \mathrm{cm}^{3}$

Subscripts

a acoustic

c calculated

e experimental

g gaseous nitrogen, $\mathrm{GN}_{2}$

1 liquid nitrogen, $\mathrm{LN}_{2}$

\section{Introduction}

Two-phase flows of liquid nitrogen, $\mathrm{LN}_{2}$, and gaseous nitrogen, $\mathrm{GN}_{2}$, were experimentally investigated. $\mathrm{LN}_{2}$ jets were injected into high-velocity $\mathrm{GN}_{2}$ streams inside a two-fluid fuel nozzle. The jets rapidly disintegrated into clouds of very small droplets. As a result, cryogenic sprays having relatively large droplet surface-areas per unit volume of liquid were produced. High surface-area fuel sprays are desirable since they provide rapid vaporization and efficient combustion of liquid fuel sprays in gas-turbine and rocket combustors. However, in order to calculate vaporization and burning rates of fuel sprays, dropsize data are needed that will accurately represent sprays in terms of a characteristic dropsize, such as the volume-median drop diameter, $D_{y .5}$, used in this study. Dropsize data were obtained for cryogenic sprays and used to derive correlating expressions for two-fluid atomization, in terms of interacting aerodynamic and liquid surface forces. Such information is needed for analytical modeling of fuelspray combustion processes. Also, fuel-spray dropsize correlations are needed that will cover wide ranges of properties of liquid fuels and atomizing gases. This will aid in the development of more efficient fuel nozzles and thereby improve combustor performance.

Highly volatile cryogenic liquid sprays containing relatively large numbers of very small droplets vaporize quite rapidly. This is due to the presence of high thermal gradients that exist in the gas-film surrounding the droplets. In the present study, the atomizing-gas was close to room temperature, $293 \mathrm{~K}$. As a result, the 
original characteristic dropsize initially formed at the atomizer orifice was not measured directly. However, it was possible to determine the original value of $D_{v .5}$, by calculating the amount it changed due to evaporation. Vaporization rates were calculated from heat-transfer and drag coefficient data that had been previously obtained for drops accelerating and vaporizing in highvelocity gasflows. Such data are difficult to obtain, especially when the droplets are microscopic in size and attain relatively high velocity in a very short distance.

In the present study of cryogenic sprays, characteristic dropsize measurements were obtained with a scattered-light scanner. It was originally developed at NASA Lewis Research Center. The instrument was improved optically, as described in Ref. 2. As a result, accurate dropsize measurements were obtained even in the presence of high velocity and high gas-density gradients. Therefore it was possible to determine the effect of droplet vaporization on experimental dropsize measurements, with the improved instrument. Also, it should be noted that sonic gas-velocity conditions were used in this study and liquid-jet breakup occurred in the regime of aerodynamic stripping.

The effect of atomizing gas flowrate on liquid jet breakup in gas streams has been reported in Refs. 1 to 7 . In Ref. 1, water sprays were formed with a two fluid atomizer. The volume median drop diameter, $D_{v .5}$, was measured for each spray and correlated with atomizing gas flowrate to give the following general expression: $\mathrm{D}_{\mathrm{v} .5}^{-1}=\mathrm{k}_{\mathrm{c}} \mathrm{W}_{\mathrm{g}}^{\mathrm{n}}$, where $\mathrm{W}_{\mathrm{g}}$ is $\mathrm{GN}_{2}$ flowrate. Atomization theory, Ref. 8 , predicts that $n=1.33$ for the case of liquid jet breakup in high velocity gasflow, i.e., in the regime of aerodynamic stripping.

Numerous investigators, as indicated in Refs. 1 to 7 , have studied the effect of gas velocity, $V_{g}$, on liquid-jet breakup in gas streams. Their results are summarized in Table 1. In the study of water-jet breakup that is described in Ref. 1, good agreement was obtained with atomization theory when the exponent $n$ was determined. However, in the case of $\mathrm{LN}_{2}$ sprays, good agreement with atomization theory may not occur. This can be attributed to the fact that highly volatile sprays can become partially vaporized. In Ref. 1 , the study of water sprays showed a marked effect of droplet vaporization on measurements of $D_{v .5}$, when sampling distance downstream of the atomizer orifice was increased from 2.2 to 4.4 and $6.7 \mathrm{~cm}$.

In the present study, original values of $D_{v .5}$ for $\mathrm{LN}_{2}$ sprays, i.e., prior to their partial vaporization, were calculated over a range of atomizing-gas flowrates. To do this, heat transfer and drag coefficient expressions obtained from Ref. 9 were used to calculate changes in dropsize that occurred due to partial vaporization of the sprays. Thus, values of $\Delta D_{\mathrm{v} .5}$ produced by droplet vaporization could be calculated and used to determine the original value of $D_{v .5}$ that existed before vaporization occurred. $\mathrm{LN}_{2}$ sprays were injected into a low velocity, $5 \mathrm{~m} / \mathrm{sec}$ airflow. Fluid pressures for $\mathrm{LN}_{2}$ and $\mathrm{GN}_{2}$ were varied over a range of 0.2 to $1.0 \mathrm{MPa}$ and the entire spray was sampled with a $4.4-$ by $1.9-\mathrm{cm}$ rectangular laser beam. The center line of the laser beam was located at an axial distance of $1.2 \mathrm{~cm}$ downstream of the fuel nozzle orifice.

\section{Apparatus and Procedure}

As shown in Fig. 1, a two-fluid fuel nozzle was mounted at the center line of the 24-cm diameter duct and operated over pressure ranges of 0.2 to $1.0 \mathrm{MPa}$ for both liquid nitrogen, $L_{2}$, and the atomizing gas, gaseous nitrogen, $\mathrm{GN}_{2}$. $\mathrm{LN}_{2}$ sprays were injected downstream into the airflow. The two-fluid nozzle was fabricated as shown in Fig. 2, with an orifice diameter of $0.66 \mathrm{~cm} . \mathrm{LN}_{2}$ at a temperature of $77 \mathrm{~K}$ was axially injected into the airstream by gradually opening the control valve until the desired flowrate of $51 \mathrm{~g} / \mathrm{s}$ was obtained as indicated by a turbine flowmeter. $\mathrm{GN}_{2}$ was then turned on and weight flowrate was measured with a $0.51-\mathrm{cm}$ diameter sharp-edge orifice. After the air; atomizing-gas and $\mathrm{LN}_{2}$ flowrates were set, the volume median diameter of the spray, $D_{v .5}$, was measured at a distance of $1.5 \mathrm{~cm}$ downstream of the atomizer orifice.

The scattered-light scanner consisted of a laser beam expander with spatial filter, rotating scanning slit and detector, as shown in Fig. 1. The instrument measured light as a function of light scatter angle, by repeatedly sweeping a variable-length slit in the focal plane of the collecting lens. The data obtained is scattered-light energy, which is a function of the scatter angle relative to the laser beam axis. This particle size measuring method is similar to that described in Ref. 10 .

Measurements of scattered-light energy normalized by the maximum energy and plotted against scattering angle can be used to determine the volume median diameter, $D_{y .5}$, as discussed in Ref. 11 and illustrated in Fig. 3. Dropsize distribution dispersion can also be determined from this plot. Also, according to this method, measurements are independent of particle distribution function. For a typical measurement, the scan is repeated 60 times per second to average out temporal variations in the energy curve. Thus, spray pattern effects were minimized by measuring an average characteristic drop diameter, $D_{v .5}$, for the entire cloud of droplets. 
Calibration was accomplished with five sets of monosized polystyrene spheres having diameters of 8,12 , 25,50 , and $100 \mu \mathrm{m}$. $L_{2}$ sprays were sampled fairly close to the atomizer orifice and they contained relatively high number-density droplets. As a result, it was necessary to correct for multiple scattering as described in Ref. 12. Measurement corrections also included Mie scattering theory when very small droplet diameters, i.e., $<\mathbf{1 0} \mu \mathrm{m}$, were measured. Dropsize measurements agreed within \pm 5 percent, as indicated by reproducibility tests. Corrections for background scattering caused by high velocity gradients in the laser beam were made by obtaining new background readings, whenever gas velocity was changed and prior to turning on the spray.

\section{Experimental Results}

$\mathrm{LN}_{2}$ spray measurements of experimental dropsize $D_{\text {v.5e }}$ were obtained with the scattered-light scanner located $1.5 \mathrm{~cm}$ axially downstresm of the two-fluid fuel nozzle. Drop velocity, $V_{d}$, was based on $D_{v .5 e}$ and drag coefficients were calculated from expressions derived in previous studies using a high-speed droplet tracking camera developed at NACA Lewis laboratory. The technique is described in Ref. 9. Resulting values of $V_{d}$ and $C_{d}$ were used to calculate vaporization time $\Delta t$, which was then used to determine $\Delta D_{v .5}^{2}$. Finally, calculated values of $D_{v .5 c}$ were obtained and used to write an expression for the originally unvaporized $\mathrm{LN}_{2}$ spray in terms of the effect of atomizing gas flow on $D_{v .5 c}$.

Correlation of $\mathrm{D}_{\mathrm{v} .5 e}{\text { with } \mathrm{GN}_{2} \text { Flowrate }}_{2}$

The entire $\mathrm{LN}_{2}$ spray cross section was sampled at $1.5 \mathrm{~cm}$ axially downstream of the two fluid fuel nozzle. Values of the reciprocal volume median diameter, $D_{v .5 e}^{-1}$ were measured and plotted against $\mathrm{GN}_{2}$ flowrate, $\mathrm{W}_{\mathrm{g}}$ as shown in Fig. 4. Since the tests were conducted in high velocity gasflow, $\mathrm{LN}_{2}$ jet breakup occurred primarily in the regime of aerodynamic stripping. From the plot shown in Fig. 5, the following correlation of reciprocal $D_{v .5 e}$ with atomizing gas flowrate, $W_{g}$, was obtained:

$$
\mathrm{D}_{\mathrm{v} .5 \mathrm{e}}^{-1}=301 \mathrm{~W}_{\mathrm{g}}^{1.11}
$$

where $D_{v .5 e}$ and $W_{g}$ are expressed as $\mathrm{cm}^{-1}$ and $\mathrm{g} / \mathrm{sec}$, respectively.

The exponent 1.11 for $W_{g}$ is considerably less than 1.33 , which is predicted by theory for liquid jet breakup in high velocity gasflow. This discrepancy is assumed to be due to a loss of small vaporizing $\mathbf{L N}_{2}$ droplets, prior to spray measurements. In Ref. 2 it was found that at a $\mathrm{LN}_{2}$ flowrate of $76.5 \mathrm{~g} / \mathrm{sec}$ the exponent $\mathrm{n}$ agreed with atomization theory. However in the present study, the $\mathrm{LN}_{2}$ flowrate was set at a lower value, i.e., $51 \mathrm{~g} / \mathrm{sec}$. This was due to the fact that high $\mathrm{LN}_{2}$ flowrate readings often indicated excessive $\mathrm{N}_{2}$ vapor entrainment in the $\mathrm{LN}_{2}$ jets, which is detrimental to the atomization process because a high pressure drop and flowrate can cause "flash" boiling breakup of the liquid jet to occur at the nozzle orifice. This phenomena was not studied.

Experimental results obtained in the present study agree better with atomization theory than those reported in Ref. 2. This is due to the allowance made in the present study for the effect of droplet vaporization on volatile liquid dropsize measurements. This effect was not accounted for in Ref. 2. As a result, dropsize data did not give agreement with the theoretically predicted gasflow exponent, $n$, in the expression, $D_{v .5}^{-1}=k W_{g}^{n}$. However, the proportionality constant $k$ was too low to adequately characterize the original spray. This was attributed to the fact that the study in Ref. 2 did not take into account the effect of small droplets vaporizing completely, before dropsize measurements could be taken.

\section{$\mathrm{LN}_{2}$ Droplet Velocity Calculations}

To determine the effect of droplet vaporization rate on experimental values of $D_{v .5 e}$ it was necessary to calculate vaporization time, $t$, by first calculating droplet velocity, $V_{d}$, for $D_{v .5 e}$ over a distance of $0.13 \mathrm{~cm}$ in the nozzle throat and a distance of $2.2 \mathrm{~cm}$ from the nozzle orifice, $x=0$, to the downstream edge of the laser beam, as shown in Fig. 1. In order to determine volume-median drop velocity, $V_{d}$, the acceleration, $a$, of $\mathrm{LN}_{2}$ droplets was calculated from the following momentum balance:

$$
m_{d}^{a}=\frac{1}{2} \rho_{g} A_{d}\left(V_{g}-V_{d}\right)^{2} C_{d}
$$

where $m_{d}$ and $A_{d}$ are mass and area of dropsize $D_{v .5 e}$, respectively, i.e., $m_{d}=\rho_{1} \pi D_{v .5 \epsilon}^{3} / 6$, and $C_{d}$ is drag coefficient for $D_{v .5 e}$. Rewriting this expression, in terms of change in drop velocity squared, $\Delta V_{d}^{2}$, over the distance of travel, $\Delta x$, the following relationship is obtained;

$$
\frac{\Delta V_{d}^{2}}{\Delta x}=\frac{3}{2} \frac{\rho_{g}}{\rho_{1}} \frac{\left(V_{g}-V_{d}\right)^{2}}{D_{v .5 e}} C_{d}
$$


where $C_{d}=27 R^{0.84}$, as given in Ref. 9, and $R e$ is based on the characteristic dropsize, $D_{\mathrm{v} .5}$.

To determine momentum transferred from $\mathrm{GN}_{2}$ flow to the $\mathrm{LN}_{2}$ droplets, the deceleration of an atomizing gaseous nitrogen jet into a surrounding low velocity airflow was determined as follows. At the nozzle orifice, $\mathrm{GN}_{2}$ velocity, $\mathrm{V}_{\mathrm{g}}$ was equal to the acoustic velocity, $\mathrm{V}_{c}$, of gaseous nitrogen. Values of $V_{g}$ that were used to solve Eq. (3), were calculated at downstream distances of $x=0,2.2$, and $5 \mathrm{~cm}$, respectively and plotted in Fig. 5. The calculated values of $\mathrm{V}_{\mathrm{g}}^{2}$ are based on data given in Ref. 13. These data are also plotted in Fig. 5 for comparison. The percent deceleration of the atomizing nitrogen gas is assumed to be approximately the same in both cases, since the two-fluid nozzles used in Ref. 13 and the present study were very similar in design.

By means of graphical integration, values of $V_{d}^{2}$ were calculated and plotted against downstream distance, $x$, as shown in Fig. 6. $\mathrm{LN}_{2}$ droplet vaporization time $\Delta t$ was calculated from this plot and the expression $\Delta t=x / \nabla_{d}$. Calculated values of $\Delta t$ for a given distance $\Delta x$ are given in Table 2 along with calculated Reynolds numbers and drag coefficients averaged over the $\Delta x$ distance. Gas and liquid transport properties used in calculating vaporization times are given in Table 3. Also, it should be noted that initially, in the nozzle throat, i.e., $\Delta x=-0.127$ to $0 \mathrm{~cm}$, the reciprocal value of $D_{v .5}$ is the same as that given in Fig. 4 for $D_{\mathrm{v} .5 \mathrm{c}}$. Whereas at $\Delta \mathrm{x}=0$ to $2.2 \mathrm{~cm}$, it decreased to the value of $D_{v .5 e}$.

\section{Spray Vaporization Rate Calculations}

The vaporization rate of cryogenic sprays characterized by $D_{v .5}$ were obtained by using the following heat-balance equation: $d m_{d} / d t=h A \Delta T / H_{t}$, where $h$ is the heat-transfer coefficient, $A$ is droplet surface-area, based on $D_{v .5}, \Delta T=T_{g}-T_{d}$, and $H_{t}=H v$ $+\mathrm{Cp} \Delta \mathrm{T}$, where $\mathrm{H}_{\mathrm{v}}$ is the latent heat of vaporization of liquid nitrogen and $C_{p}$ is the specific heat of gaseous nitrogen. This expression may be rewritten as follows to obtain vaporization rate in terms of changes in droplet surface-area with time:

$$
\mathrm{dD}_{\mathrm{v} .5}^{2} / \mathrm{dt}=4 \mathrm{k}_{\mathrm{g}} \Delta \mathrm{T} \mathrm{Nu} / \rho_{1} \mathrm{H}_{\mathrm{t}}
$$

where $\mathrm{k}_{\mathrm{g}}$ and $\rho_{1}$ are gas thermal conductivity and liquid density, respectively. In a previous fuel-droplet study using a high-speed droplet tracking camera to determine vaporization rates for fuels such as n-octane and methanol, as well as numerous other liquids includ- ing water, benzene, acetone, nitrobenzene, butanol, and carbon tetrachloride, it was found that: $\mathrm{Nu}=2$ $+0.303 \operatorname{Re}^{0.6}$ where $\operatorname{Re}=\rho_{\mathrm{g}} \mathrm{D}_{\mathrm{v} .5} \Delta \mathrm{V} / \mu_{\mathrm{g}}$, and $\Delta \mathrm{V}$ is the average velocity difference over an incremental distance $\Delta \mathbf{x}$.

To calculate vaporization time, $t$, inside the twofluid nozzle, an average value of $v_{d}^{2}$ was taken between $x=-0.13$ and $0 \mathrm{~cm}$, and used to calculate $\Delta t$, i.e., $\Delta t=\Delta x / \bar{V}_{\text {d }}$. In a similar manner, the average Reynolds number, $\mathrm{R}_{e}$, was determined by averaging Reynolds numbers over a distance of $0.13 \mathrm{~cm}$. Fe and $t$ were then used in heat-transfer calculations to determine $\mathrm{LN}_{2}$ droplet vaporization rates. Calculations were based on characteristic diameters $D_{v .5 c}, D_{v .5 e}$ and transport properties listed in Table 3. $\mathrm{GN}_{2}$ viscosity and thermal conductivity were evaluated at the average gas-film temperature, i.e., $T_{f}=1 / 2\left(T_{g}+T_{1}\right)$. Droplet surface temperatures were assumed to be near the boiling point, $77 \mathrm{~K}$, while droplet sprays were being accelerated and partially vaporized. The latent heat of vaporization of $\mathrm{LN}_{2}$ was evaluated at $77 \mathrm{~K}$ and the specific heat of nitrogen vapor was evaluated at the average gas-film temperature, $T_{r}$.

Calculated values of the change in characteristic droplet diameter squared, $D_{v, 5}^{2}$, that occurs due to partial vaporization of the sprays, are given in Table 4. The calculation was made for gaseous-nitrogen and liquid-nitrogen flowrates of 1.82 and $51 \mathrm{~g} / \mathrm{sec}$, respectively. Calculated values of $D_{v .5 c}^{2}$, were obtained from the expression; $-\Delta D_{v .5}^{2}=D_{v .5 c}^{2}-D_{v .5 e}^{2}$. Values of $D_{v .5 e}^{-1}$ are plotted against $\mathrm{GN}_{2}$ flowrates as shown in Fig. 4. From this plot, the following correlating expression is obtained for calculated values of $D_{v .5 c}$;

$$
D_{\mathrm{v} .5 \mathrm{c}}^{-1}=285 \mathrm{~W}_{\mathrm{g}}^{1.33}
$$

In terms of the Sauter mean diameter, $D_{32}$, it was found that Eq. (5) can be rewritten as; $D_{32 c}^{-1}=422 \mathrm{~W}_{\mathrm{g}}^{1.33}$.

Comparison of Eq. (5) with Eq. (1), shows that the exponent 1.33 for gas flowrate in Eq. (5) is considerably greater than 1.11, as given in Eq. (1) for experimental values of $D_{v .5 e}$. Equation (5) is in good agreement with atomization theory and the proportionality constant, 285 is only slightly less than the value of 301 given in Eq. (1). Thus, droplet vaporization had considerable effect on the exponent, $n$, but only a small effect on the constant, $k$. Also, it should be noted that Eq. (5) is useful in establishing the initial values of $D_{v .5}$ that are needed in analytical modeling of cryogenic 
liquid spray vaporization and combustion, on a macroscopic scale.

The expression, $D_{v .5}^{-1}=k_{c} W_{g}^{n}$ used in the present study of $\mathrm{LN}_{2}$ sprays cannot be directly compared with expressions obtained in previous studies of water sprays, until the effect of atomizing-gas temperature on $\mathrm{LN}_{2}$ spray formation has been investigated and determined. In the case of $\mathrm{LN}_{2}$ and water sprays, the exponent $n$ should equal 1.33 in agreement with atomization theory. However, the value of $\mathbf{k}$ will be considerably different due to large differences in their properties. The effect of atomizing-gas properties on $\mathrm{LN}_{2}$ jet breakup also needs to be further investigated.

\section{Concluding Remarks}

It was possible to determine the effect of droplet vaporization on cryogenic spray measurements because previous studies in Ref. 9 were able to provide heat and momentum transfer expressions for droplets accelerating and vaporizing in high velocity gasflows. As a result, an originally unvaporized volume-mean diameter, $D_{v .5 c}$ ' could be calculated for $\mathrm{LN}_{2}$ sprays produced with twofluid fuel nozzles. The results agree well with atomization theory and can be readily applied to analytical modeling of fuel spray combustion in gas turbine and rocket combustors, under the conditions used in the present study. Dropsize data for different atomizing gases and wide ranges of gas temperature are needed in order to generalize the expressions derived in this study of $\mathrm{GN}_{2}$ and $\mathrm{LN}_{2}$.

\section{References}

1. Ingebo, R.D., "Experimental and Theoretical Effects of Nitrogen Gas Flowrate on Liquid Jet Atomization," Journal of Propulsion and Power, Vol. 4, No. 6, Nov.-Dec. 1988, pp. 406-411.

2. Ingebo, R.D., and Buchele, D.R., "Scattered-Light Scanner Measurements of Cryogenic Liquid-Jet Breakup," NASA TM-102432, 1990.

3. Kim, K.Y., and Marshall, W.R., Jr., "Drop Size Distributions from Pneumatic Atomizers," AIChE Journal, Vol. 17, No. 3, May 1971, pp. 575-584.

4. Lorenzetto, G.E., and Lefebvre, A.H., "Measurements of Drop Size on a Plain-Jet Airblast Atomizer," AIAA Journal, Vol. 15, No. 7, July 1977, pp. 1006-1010.

5. Nukiyama, S., and Tanasawa, Y., "Experiments on the Atomization of Liquids by Means of a Air
Stream, Parts III-IV," Transactions of the Society of Mechanical Engineers, Japan, Vol. 5, No. 18, Feb. 1939, pp. 63-75.

6. Weiss, M.A., and Worsham, C.H., "Atomization in High Velocity Airstreams," American Rocket Society Journal, Vol. 29, No. 4, Apr. 1959, pp. 252-259

7. Wolf, H.E., and Andersen, W.H., "Aerodynamic Break-up of Liquid Drops," in Proceedings of the 5th International Shock Tube Symposium, edited by Z.I. Slawasky, J.F. Moulton, Jr., and W.S. Filler, Naval Ordnance Lab., White Oak, MD, 1966, pp. 1145-1169. (Avail. NTIS, AD-638011.)

8. Adelberg, M., "Mean Drop Size Resulting From The Injection of a Liquid Jet Into a High Speed Gas Stream," AIAA Journal, Vol. 6, No. 6, June 1986, pp. $1143-1147$.

9. Ingebo, R.D., "Atomization, Acceleration and Vaporization of Liquid Fuels," in Sixth Symposium (International) on Combustion, Reinhold Publishing Corporation, New York, 1957, pp. 684-687.

10. Swithenbank, J., Beer, J.M., Taylor, D.S., Abbot, D., and McCreath, G.C., "A Laser Diagnostic Technique for the Measurement of Droplet and Particle Size Distribution," in Experimental Diagnostics in Gas Phase Combustion Systems, edited by B.T. Zinn and C.T. Bowman, Progress in Astronautics and Aeronautics, Vol. 53, AIAA, New York, 1977, pp. 421-447.

11. Buchele, D.R., "Particle Sizing by Weighted Measurements of Scattered Light," NASA TM-100968, 1988.

12. Felton, P.G., Hamidi, A.A., and Aigal, A.K., "Measurement of Drop-Size Distribution in Dense Sprays by Laser Diffraction," from No. 12: ICLASS-86; Proceedings of the Third International Conference on Liquid Atomization and Spray Systems, Vol. 2, edited by P. Eisenklam and A. Yule, Institute of Energy, L o n d o n, U.K., 1985 , pp. IVA/4/1-IVA/4/11.

13. Bulzan, D.L., Levy, Y., Aggarwal, S.K., and Chitre, S., "Measurements and Predictions of a Liquid Spray From an Air-Assist Nozzle," AIAA Paper 91-0692, Jan. 1991. (Also, NASA TM-103640, 1991.) 
TABLE 1.-ATOMIZING-GAS VELOC-

ITY EXPONENT, n, FOR LIQUID-

NITROGEN JET BREAKUP,

\begin{tabular}{|l|c|}
\hline \multicolumn{3}{|c|}{$\mathrm{D}_{\mathrm{c}} \sim \mathrm{V}_{\mathrm{g}}^{-\mathrm{n}}$} \\
\hline \multicolumn{1}{|c|}{ Source (Ref.) } & Exponent \\
\hline Kim and Marshall (3) & 1.33 \\
Lorenzetto and Lefebvre (4) & 1.00 \\
Nukiy ama and Tanasawa (5) & 1.14 \\
Weiss and Worsham (6) & 1.33 \\
Wolf and Anderson (7) & ${ }^{\mathrm{a}} 1.33$ \\
Adelberg, (theory) (8) & 1.33 \\
Present study & 1.33 \\
\hline
\end{tabular}

${ }^{a}$ Wax sphere dropsize data.

TABLE 2.-CALCULATED $\mathrm{LN}_{2}$ DROPLET

VAPORIZATION TIME, $\triangle T$, FOR $D_{v .5}$,

\begin{tabular}{|c|c|c|c|c|}
\hline \multicolumn{1}{|c}{$\mathrm{AT} \mathrm{W}_{\mathrm{g}}=1.82 \mathrm{~g} / \mathrm{sec}$} \\
\hline $\begin{array}{c}\Delta \mathrm{x}, \\
\mathrm{cm}\end{array}$ & $\mathrm{Re}^{\mathrm{a}}$ & $\mathrm{C}_{\mathrm{d}}$ & $\begin{array}{c}\Delta \mathrm{tx} 10^{4} \\
\mathrm{sec}\end{array}$ \\
\hline $\begin{array}{c}\text { Inside nozzle } \\
\text { Downoat } \\
\text { of nozzle }\end{array}$ & 0.13 & 70 & 0.76 & 0.47 \\
Total & 2.2 & 35 & 1.36 & 3.26 \\
\hline
\end{tabular}

${ }^{\mathrm{a}} \mathrm{Re}=\mathrm{RE} \mathrm{E}_{1} \Delta \mathrm{t}_{1} / \mathrm{t}_{\mathrm{t}}+\operatorname{Re}_{2} \Delta \mathrm{t}_{2} / \mathrm{t}_{\mathrm{t}}$

bInside fuel nozzle.

c Outside of fuel nozzle.
TABLE 3.-ATOMIZING-GAS AND

LIQUID-JET TRANSPORT PROP-

$$
\begin{gathered}
\text { ERTIES, AT } W_{g}=4.54 \mathrm{~g} / \mathrm{sec} \\
\mathrm{T}_{\mathrm{g}}=293 \mathrm{~K}, \mathrm{~T}_{1}=77 \mathrm{~K} \\
\text { AND } \mathrm{x}=-0.127 \mathrm{~cm}
\end{gathered}
$$

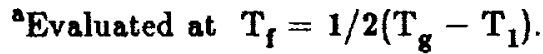

TABLE 4--REDUCTION IN DROPSIZE

\begin{tabular}{|c|c|c|c|}
\hline \multicolumn{4}{|c|}{ DROPSIZE, $D_{Y=5}^{-1}$} \\
\hline $\begin{array}{c}W_{g^{\prime}} \\
g / \mathrm{sec}\end{array}$ & $-\frac{\Delta \mathrm{D}_{\mathrm{v} .5}^{2} \times 10^{8}}{\mathrm{~cm}^{2}}$ & $\begin{array}{c}\mathrm{D}_{\mathrm{v} .5 \mathrm{e}^{2}}^{2} \times 10^{8} \\
\mathrm{~cm}^{2}\end{array}$ & $\begin{array}{c}D_{\mathrm{v}}^{-1}-5 \mathrm{f}^{\prime} \\
\mathrm{cm}^{\prime}\end{array}$ \\
\hline 1.82 & 37.0 & 289 & 630 \\
\hline 2.72 & 21.2 & 113 & 1044 \\
\hline 3.63 & 19.3 & 62 & 1530 \\
\hline 4.54 & 17.6 & 39 & 2162 \\
\hline
\end{tabular}
DUE TO VAPORIZATION, $-\Delta \mathrm{D}_{\mathrm{v} .5}^{2}$, AND CALCULATED ORIGINAL

${ }^{\Delta} D_{v .5 c}^{-1}=\left(D_{v .5 e}^{2}-\Delta D_{v .5 c}^{2}\right)^{-0.5}$. 


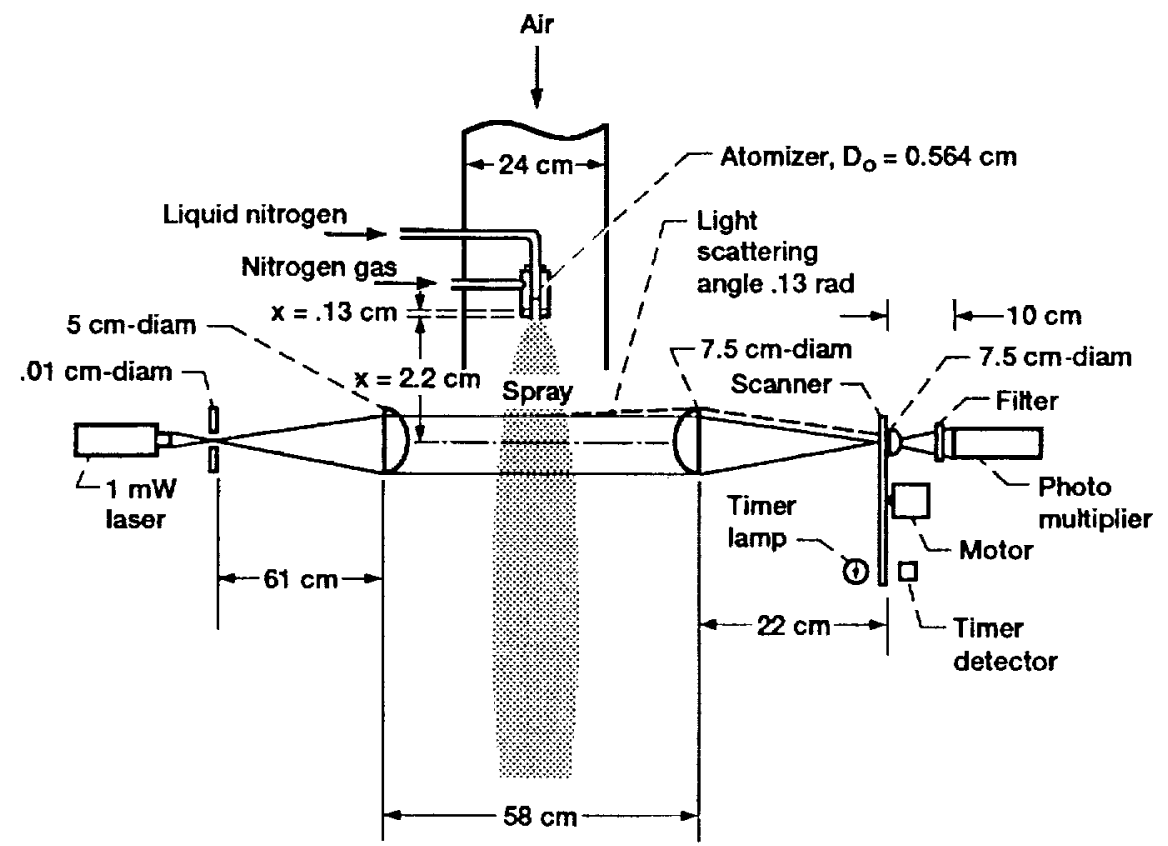

Figure 1.-Atmospheric pressure test section and optical path of scattered-light scanner.

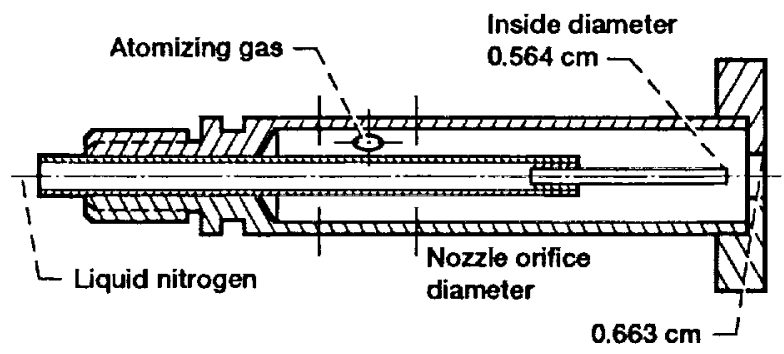

Figure 2.-Diagram of pneumatic two-fluid atomizer.

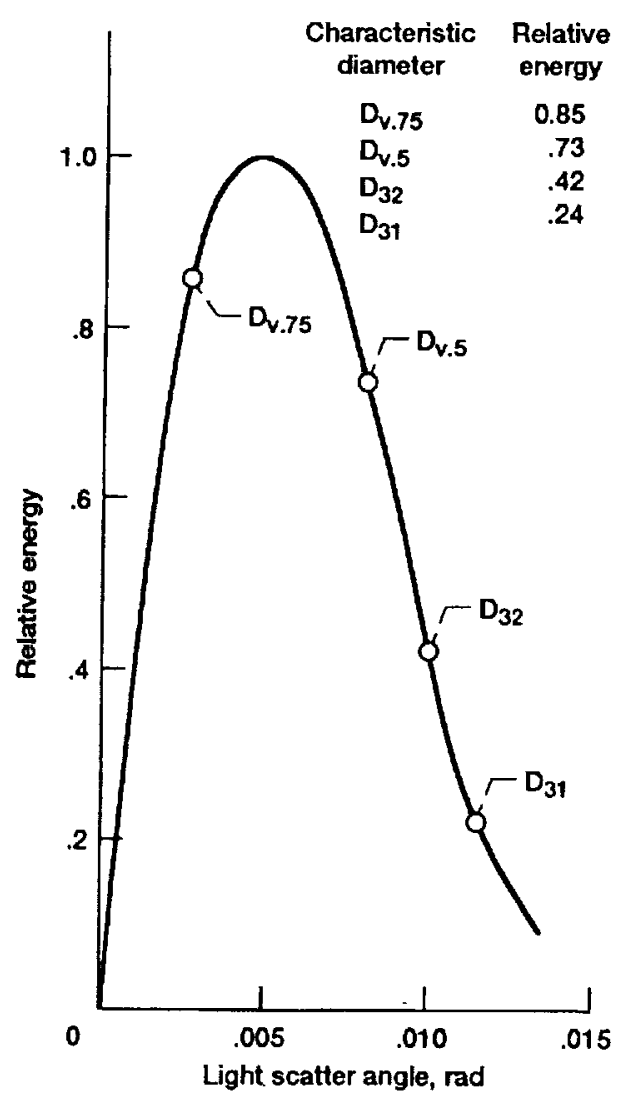

Figure 3.-Typical scattered-light energy curve with four characteristic diameters. 


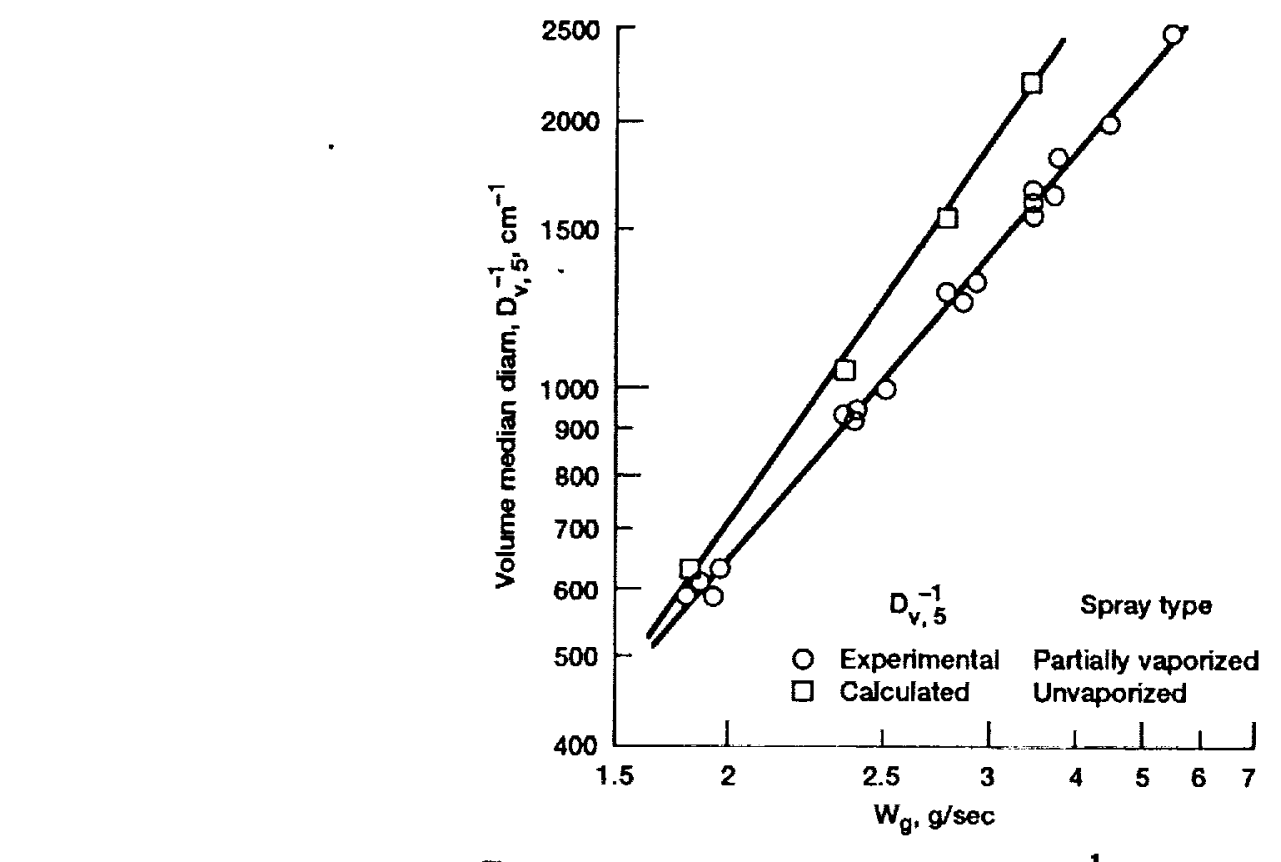

Figure 4.-Effect of alomizing-gas flowrate on $D_{v, 5}^{-1}$, for partially vaporized and unvaporized cryogenic-liquid sprays.

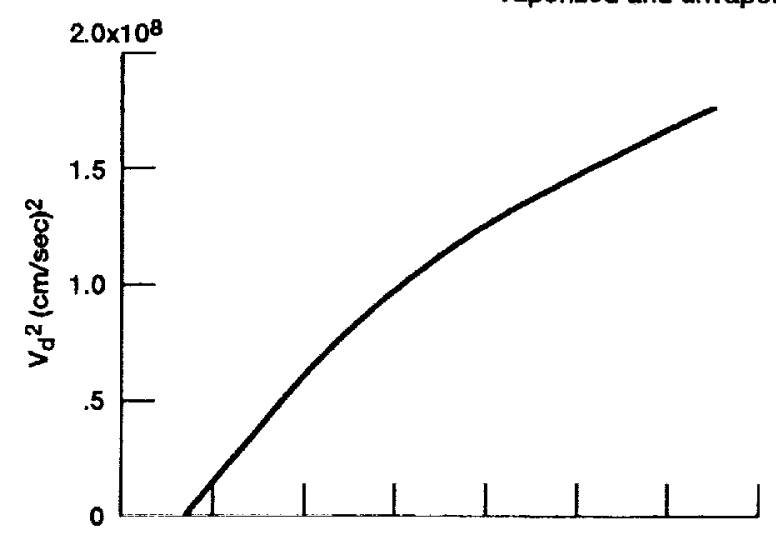

(a) $W_{\mathrm{g}}=1.82 \mathrm{~g} / \mathrm{sec}$.

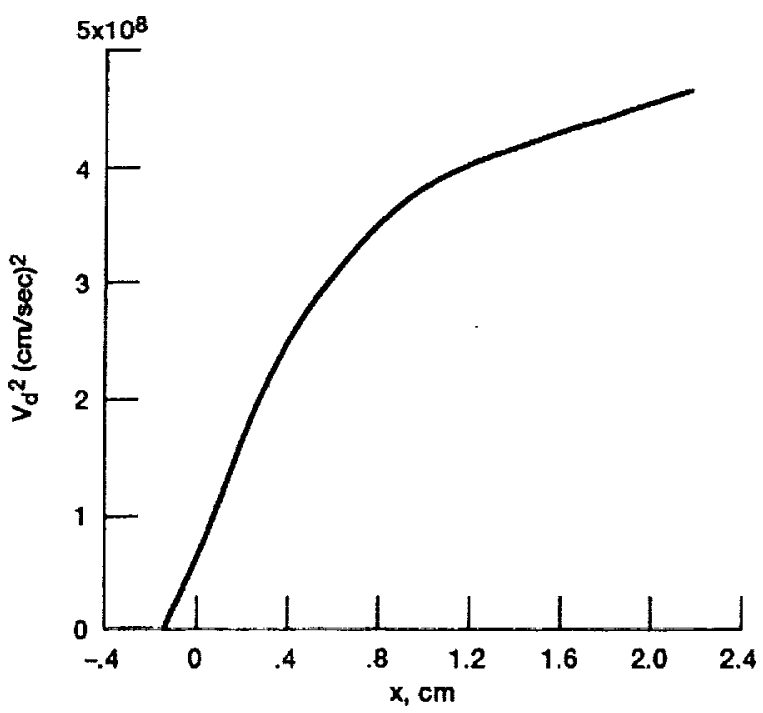

(b) $W_{\mathrm{g}}=4.54 \mathrm{~g} / \mathrm{sec}$.

Figure 5.-Acceleration of characteristic $L_{2}$ dropsize, $D_{v}, 5$.

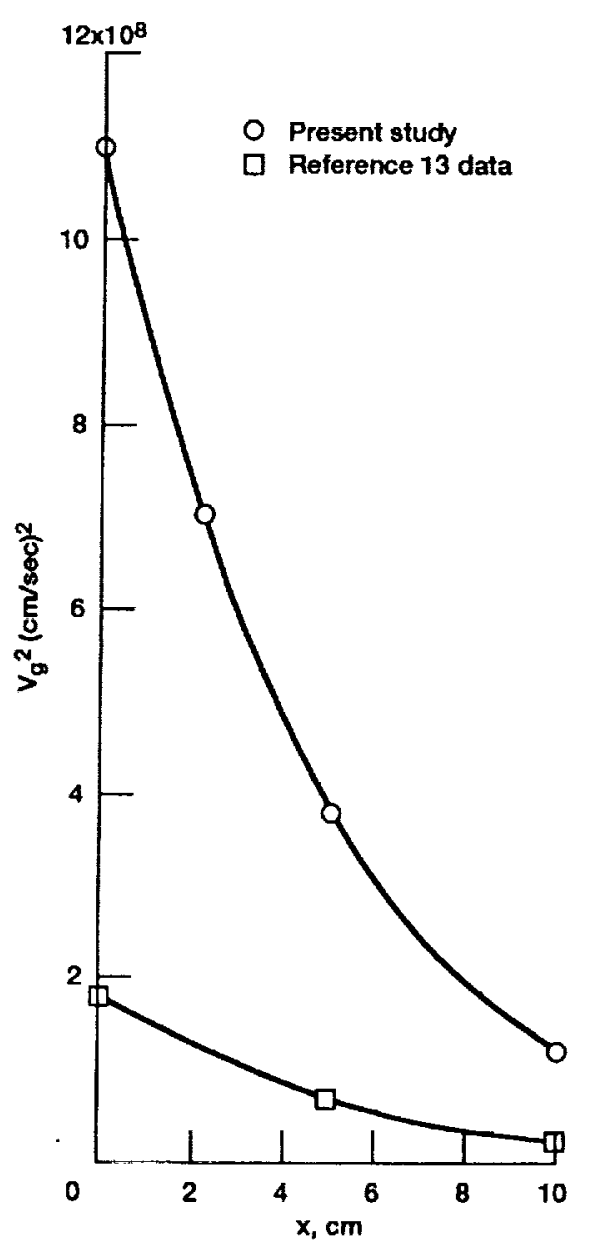

Figure 6.-Deceleration of atomizing gas downstream of fuel nozzle. 


\begin{tabular}{|c|c|c|c|}
\hline \multicolumn{3}{|c|}{ REPORT DOCUMENTATION PAGE } & $\begin{array}{l}\text { Form Approved } \\
\text { OMB No. 0704-0188 }\end{array}$ \\
\hline \multicolumn{4}{|c|}{ 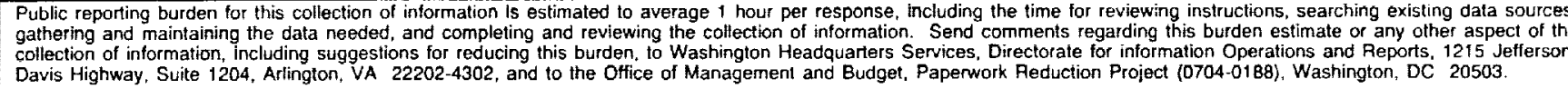 } \\
\hline 1. AGENCY USE ONLY (Leave blank) & $\begin{array}{r}\text { 2. REPORT DATE } \\
\text { October } 1992\end{array}$ & \multicolumn{2}{|c|}{$\begin{array}{l}\text { 3. REPORT TYPE AND DATES COVERED } \\
\text { Technical Memorandum }\end{array}$} \\
\hline \multicolumn{3}{|c|}{$\begin{array}{l}\text { 4. TITLE AND SUBTITLE } \\
\text { Effect of Vaporization on Cryogenic Spray Dropsize Measurement }\end{array}$} & \multirow{2}{*}{$\begin{array}{l}\text { 5. FUNDING NUMBERS } \\
\text { WU-505-62-21 }\end{array}$} \\
\hline \multicolumn{3}{|l|}{$\begin{array}{l}\text { 6. AUTHOA(S) } \\
\text { Robert D. Ingebo }\end{array}$} & \\
\hline \multicolumn{3}{|l|}{$\begin{array}{l}\text { National Aeronautics and Spac } \\
\text { Lewis Rescarch Center } \\
\text { Cleveland, Ohio } 44135-3191\end{array}$} & $\begin{array}{l}\text { 8. PERFORMING ORGANIZATION } \\
\text { REPORT NUMBER }\end{array}$ \\
\hline \multicolumn{3}{|c|}{ 9. SPONSORING/MONITORING AGENCY NAMES(S) AND ADDRESS(ES) } & $\begin{array}{l}\text { 10. SPONSORING/MONITORING } \\
\text { AGENCY REPORT NUMBER }\end{array}$ \\
\hline
\end{tabular}

11. SUPPLEMENTARY NOTES

Prepared for the 31st Acrospace Sciences Meeting and Exhibit sponsored by the American Institute of Aeronautics and Astronautics, Reno, Nevada, January 11-14, 1993. Responsible person, Robert D. Engebo, (216) 433-3586.

12a. DISTRIBUTION/AVAILABILITY STATEMENT

12b. DISTRIBUTION CODE

Unclassified - Unlimited

Subject Category 35

13. ABSTRACT (Maximum 200 words)

The fluid mechanics of multi-phase flow breakup of liquid nitrogen, $\mathrm{LN}_{2}$, jets injected into sonic velocity nitrogen gasflow, was experimentally investigated. A scattered-light scanning instrument was used to measure the characteristic dropsize, $D_{v .5}$, of $\mathrm{LN}_{2}$ sprays and to determine the effect of droplet vaporization on experimental dropsize measurements. Under sonic gas-velocity conditions, liquid-jet breakup occurred in the regime of aerodynamic stripping. As a result, the following correlation of volume-median drop diameter, $\mathrm{D}_{\mathrm{v} .5}$, with atomizing gas flowrate, $\mathrm{W}_{\mathrm{g}}$, was derived for two-fluid atomizers; with atomizing gas flowrate, $W_{g}$, was derived for two-fluid atomizers; $D_{v .5}^{-1}=k_{c}^{g} W_{g}^{n}$, where proportionally constant $k_{c}$ and exponent $n$ are functions of droplet vaporization rate. In this study, partially vaporized sprays werc investigated and it was found that $\mathbf{n}=1.11$, which is considerably less than the valuc of 1.33 that is predicted by atomization theory. This was attributed to the evaporative loss of very small droplets. As a result, the following expression was obtained experimentally: $D_{v, 5 e}^{-1}=301 \mathrm{~W}_{\mathrm{g}}^{1.11}$. Values of $\mathrm{D}_{\mathrm{v} .5}$, that existed prior to partial vaporization of the $\mathrm{LN}_{2}$ sprays: Values of $D_{v .5}$, that existed prior to partial vaporization of the $\mathrm{LN}_{2}$ sprays, were calculated and the following expression was derived for originally unvaporized $\mathrm{LN}_{2}$ sprays: $\mathrm{D}_{\mathrm{v} .5}^{-1}=285 \mathrm{~W}_{\mathrm{g}}^{1.33}$. This expression agrees well with atomization theory that predicts $n=1.33$, for liquid jet breakup in high-velocity gasflow.

14. SUBJECT TERMS

Cryogenic liquids; Fuel sprays; Dropsize correlations; Vaporization; Heat-transfer coefficients; Drag coefficients

17. SECURITY CLASSIFICATION OF REPORT

Unclassified
18. SECURITY CLASSIFICATION OF THIS PAGE Unclassified
19. SECURITY CLASSIFICATION OF ABSTRACT Unclassified 